\title{
Nordic ringtest on INDF content and NDF degradation characteristics in three feeds
}

\author{
P. Lund ${ }^{1,6}$, M.R. Weisbjerg', S. Ahvenjärvi², P. Huhtanen², P. Udén ${ }^{3}$, \\ B. Olafsson ${ }^{4}$ and H. Volden ${ }^{5}$
}

${ }^{1}$ Department of Animal Nutrition and Physiology, Danish Institute of Agricultural Sciences, Research Centre Foulum

P.O. Box 50, DK-8830 Tjele, Denmark

${ }^{2}$ Animal Production Research, MTT Agrifood Research Finland

SF-31600 Jokioinen, Finland

${ }^{3}$ Department of Animal Nutrition and Management, Kungsängen Research Centre

S-753 23 Uppsala, Sweden

${ }^{4}$ Department of Animal Nutrition, Agricultural Research Institute

Keldnaholt, IS-112 Reykjavik, Iceland

${ }^{5}$ Department of Animal Science, Agricultural University of Norway

P.O. Box 5025, N-1432 As, Norway

\begin{abstract}
NDF and indigestible NDF (INDF) content in barley, rapeseed meal and grass silage was measured in five research laboratories. NDF content (\%DM) was similar for grass silage $(50-52 \%)$, but varied from 21 to $25 \%$ in barley and from 19 to $31 \%$ in rapeseed meal. The variation in INDF content was also high, mainly due to differences in NDF analysis of the residue. Differences in effective rumen NDF degradability were also high for grass silage (52-64\%), barley $(50-70 \%)$ and rapeseed meal $(38-56 \%)$, respectively. This ringtest underlines the need for standardization of the NDF analysis and of in situ procedures.
\end{abstract}

KEY WORDS: fibre, barley, grass silage, rapeseed meal, kinetics, degradation

\section{INTRODUCTION}

Rumen fermentation of the fibre fraction is one of the most important submodels in the new dynamic feed evaluation systems. These sub-models are usually both generated and evaluated based on experimental data compiled from multiple

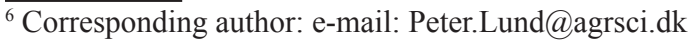


research institutes, and it is therefore crucial that the variation between laboratories in the quantitative and qualitative characteristics of the fibre fraction is minimized. The aim was therefore to compare the results from five research laboratories on fibre content and rumen degradation of three commonly used feeds.

\section{MATERIAL AND METHODS}

Barley, rapeseed meal (RSM) and freeze-dried grass silage, were ground to pass a $1.5 \mathrm{~mm}$ screen and sent to 5 research laboratories (Lab1-Lab5). NDF analysis was, in all laboratories, based on Van Soest et al. (1991), but with individual modifications. Lab1 used the Ankom method with addition of $\mathrm{Na}_{2} \mathrm{SO}_{3}$ and amylase. Lab2 used amylase only for barley and used an alternative oven method (Chai and Udén, 1998) and subsequently corrected for ash. Lab3 used the Ankom technique with addition of both amylase and $\mathrm{Na}_{2} \mathrm{SO}_{3}$, and correction for content of ash. Lab4 used the Fibertec system with the addition of $\mathrm{Na}_{2} \mathrm{SO}_{3}$ and amylase (barley only) and a subsequent correction for ash. Lab5 used addition of $\mathrm{Na}_{2} \mathrm{SO}_{3}$ and amylase and subsequent correction for ash and used the Ankom method for nylon bag residue and Fibertec for NDF in original feeds.

NDF in situ degradation was done using local procedures. Rumen effective degradability (ED, \%) was calculated based on correction for particulate loss during washing (Hvelplund and Weisbjerg, 2000) and using a fractional passage rate of $2 \% \mathrm{~h}^{-1}$ and a model including a lag time. Laboratories determined INDF (indigestible NDF) using their own nylon bag method regarding incubation time, in situ nylon bag pore size, sample weight, etc. In the five laboratories an incubation time and nylon bag pore size of $114 \mathrm{~h} / 37 \mu \mathrm{m}, 96 \mathrm{~h} / 28 \mu \mathrm{m}, 240 \mathrm{~h} / 37 \mu \mathrm{m}, 288 \mathrm{~h} / 17$ $\mu \mathrm{m}$ and $504 \mathrm{~h} / 37 \mu \mathrm{m}$, respectively, were used. Potential NDF digestibility (PD, \%) was calculated as $100 \times(\mathrm{NDF}-\mathrm{INDF}) / \mathrm{NDF}$.

To evaluate the effect of variation due to bags vs variation due to cows/NDF analysis, four laboratories (Lab1, Lab2, Lab4, Lab5) weighed each feed in eight of their own bags, and send two bags to each of the four laboratories for a six days $(144 \mathrm{~h})$ incubation. In total 32 observations on INDF content in each feed could subsequently be analysed based on effects of origin of bags and of place for incubation. Statistical analysis was done using NLIN and GLM in SAS 8.e.

\section{RESULTS}

Only minor differences were found in NDF content in barley $(\mathrm{CV}=9.4)$ and especially grass silage $(\mathrm{CV}=0.78)$, whereas for $\mathrm{RSM}$, the variation in NDF content was high $(\mathrm{CV}=19)$, and NDF varied from 19.4 to $30.8 \%$ in the DM. INDF content varied in $\%$ of DM from 4.7 to $8.1 \%$ in grass silage, from 3.3 to $5.5 \%$ in barley and from 6.4 to $12.9 \%$ in RSM. There was no relationship between a high NDF content and a high 
INDF content between laboratories, and therefore large variations were also found in PD. PD varied from 84.1 to $90.8 \%$ for grass silage, from 75.8 to $86.6 \%$ for barley and from 42.8 to $68.0 \%$ for RSM. For all three feeds, the highest INDF content and the lowest PD was found in Lab1 (144 h incubation), whereas for Lab5 (504 h incubation), PD was generally high. There was only minor differences in the form of the degradation curve for grass silage between laboratories, whereas much larger variations were seen for barley and RSM (data not shown), resulting in large variations in ED (Table 1).

Table 1. NDF (\%DM), INDF (\%DM) and in situ potential NDF digestibility (PD, \%) determined using local procedures, in situ rumen effective NDF degradability (ED, \%), mean, standard deviation (SD) and coefficient of variation $(\mathrm{CV}, \%)$

\begin{tabular}{|c|c|c|c|c|c|c|c|c|c|}
\hline Feed & & Lab1 & Lab2 & Lab3 & Lab4 & Lab5 & Mean & SD & $\mathrm{CV}$ \\
\hline \multirow{4}{*}{ Grass silage } & NDF & 51.0 & 50.8 & 51.5 & 50.4 & 51.0 & 50.9 & 0.40 & 0.78 \\
\hline & $\mathrm{INDF}^{1}$ & 8.1 & 6.9 & 6.8 & 4.9 & 4.7 & 6.3 & 1.5 & 23 \\
\hline & PD & 84.1 & 86.4 & 86.8 & 90.4 & 90.8 & 87.7 & 2.8 & 3.2 \\
\hline & ED & 52.0 & 55.8 & 59.6 & 60.8 & 63.5 & 58.3 & 4.5 & 7.7 \\
\hline \multirow{4}{*}{ Barley } & NDF & 22.5 & 20.5 & 20.6 & 24.3 & 25.2 & 22.6 & 2.1 & 9.4 \\
\hline & $\mathrm{INDF}^{1}$ & 5.5 & 4.7 & 4.3 & 3.3 & 4.2 & 4.4 & 0.80 & 18 \\
\hline & PD & 75.8 & 77.1 & 79.4 & 86.6 & 83.2 & 80.4 & 4.5 & 5.6 \\
\hline & ED & 63.9 & 50.1 & 50.7 & 70.1 & 59.2 & 58.8 & 8.6 & 15 \\
\hline \multirow{4}{*}{$\begin{array}{l}\text { Rapeseed } \\
\text { meal }\end{array}$} & $\mathrm{NDF}$ & 22.5 & 19.4 & 23.8 & 28.9 & 30.8 & 25.1 & 4.7 & 19 \\
\hline & $\mathrm{INDF}^{1}$ & 12.9 & 6.4 & 12.0 & 12.2 & 9.9 & 10.7 & 2.6 & 25 \\
\hline & PD & 42.8 & 67.0 & 49.6 & 57.7 & 68.0 & 57.0 & 11 & 19 \\
\hline & ED & 38.1 & 50.7 & 39.8 & 54.4 & 56.2 & 47.8 & 8.4 & 17 \\
\hline
\end{tabular}

${ }^{1}$ incubation time: Lab1: 114 h, Lab2: 96 h, Lab3: 240 h, Lab4: 288 h and Lab5: 504 h

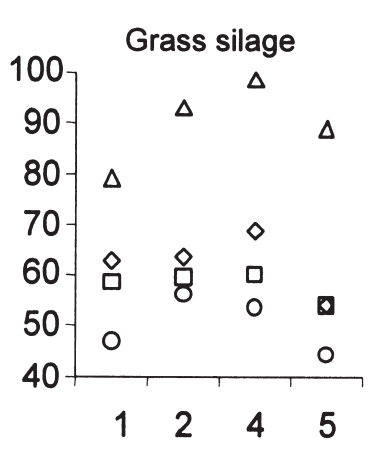

Origin of bag (Lab\#)

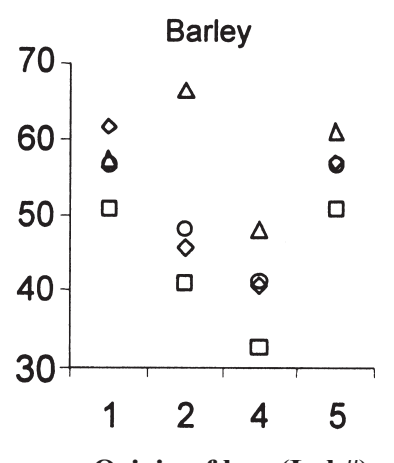

Origin of bag (Lab\#)

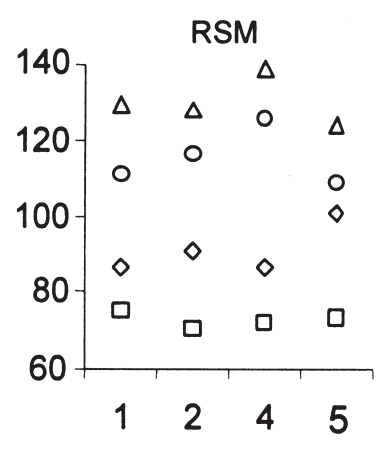

Origin of bag (Lab\#)

Figure 1. INDF content (g pr. kg DM) from bags of different origin \#(Lab1, Lab2, Lab4, Lab5) incubated for $144 \mathrm{~h}$ in different laboratories (Lab1:r, Lab2: $\square$, Lab4:○, Lab5: $\diamond)$ 
The statistical analysis on INDF residue ( $\mathrm{g}$ per $\mathrm{kg} \mathrm{DM}$ ) showed large interactions between feeds, origin of bags and place of incubation, which is illustrated in Figure 1. Across feeds, there was no significant effect of origin of bags $(\mathrm{P}=0.94)$, whereas there was a significant effect of place for incubation/ analysis $(\mathrm{P}<0.001)$. For grass silage, both origin of bags $(\mathrm{P}=0.002)$ and place for incubation/analysis $(\mathrm{P}<0.001)$ had a significant effect. Lab1 residues were highest $(90 \mathrm{~g})$ and residues from Lab4 were lowest $(50 \mathrm{~g})$. Similar effects of origin of bags $(\mathrm{P}<0.001)$ and place for incubation $(\mathrm{P}=0.004)$ was found for barley. The most pronounced effect of place of incubation was found for RSM. No significant effect $(\mathrm{P}=0.17)$ was found for origin of bags, whereas place for incubation was significant $(\mathrm{P}<0.001)$ as illustrated in Figure 1. Residue varied from on average 73 $\mathrm{g}$ for bags incubated in Lab2 to $130 \mathrm{~g}$ for Lab1.

\section{DISCUSSION}

Although laboratories based their NDF analysis on the same principles, major differences were found in problematic feeds like barley containing starch and RSM containing fat. Differences in potential digestibility was not only due to differences in incubation time or bag pore size. There were also problems with the reproducibility in the determination of residual NDF when bag type was balanced and incubation time was fixed. This could have been due to differences between cows, but more likely due to laboratory differences in losses during washing of bags and in NDF analysis of bag residues.

\section{CONCLUSIONS}

NDF content and potential digestibility of NDF are important parameters in new feed evaluation systems. Although partitioning of fibre into indigestible and potentially digestible fibre was different between laboratories, there also seemed to be problems with the reproducibility of the NDF analysis on some feeds. The variation in INDF content was primarily due to used cows, washing procedures and/or method for residual NDF analysis, and to a minor extent due to bag type.

\section{REFERENCES}

Chai W., Udén P., 1998. An alternative oven method combined with different detergent strengths in the analysis of neutral detergent fibre. Anim. Feed Sci. Tech. 74, 281-288

Hvelplund T., Weisbjerg M.R., 2000. In situ techniques for the estimation of protein degradability and postrumen availability. In: D.I. Givens, E. Owen, R.F.E. Axford, H.M. Omed (Editors). Forage Evaluation in Ruminant Nutrition. CABI Publishing, pp. 233-258

Van Soest P.J., Robertson J.B., Lewis B.A., 1991. Methods for dietary fiber, neutral detergent fiber and nonstarch polysaccharides in relation to animal nutrition. J. Dairy Sci. 74, 3583-3597 